\title{
Multimodality in Early Childhood Education
}

\author{
Kelsey C. Deklerk
}

\begin{abstract}
The purpose of this paper is to explore the uses of multimodality within early childhood education classrooms for the purposes of literacy education. Wohlwend (2008) urges educators to keep age-appropriate practices in place, even amid a shift in educational requirements and expectations. In this paper, the use of age-appropriate, multimodal practices for young learners is explored. Though there is not necessarily research specific to multimodality in early childhood, the literature shows that multimodality is present in forms of play; the use of toys, devices, and technology; drama; and social interactions. Through these modality-rich avenues, literacy development can still be achieved through engaging structures for children. Multimodality creates opportunities to position the student as the expert in their own learning and create collaborative learning environments. Potential issues with these uses of multimodality include conflicts around devices in the classroom and negative social interactions. Additional research is needed to connect the fields of multimodality and early childhood education.
\end{abstract}

Keywords: Multimodality, Early Childhood Education, Literacy Education, Play, Developmentally Appropriate Practices

\section{Introduction}

In an age of high-stakes testing, we are finding that students are being given fewer opportunities for play within educational settings, and even losing recess time to allow for more structured academic time (Blatchford et al., 2016; Bassok et al., 2016; Christakis, 2016). As technology evolves, there are more opportunities for creative engagement in material and instructional techniques. With an understanding of how children learn and grow, there is also an interest in re-engaging students in instructional techniques and educational practices that are exciting and developmentally appropriate and push for students' growth and understanding. In education,

Contact: Kelsey C. Deklerk, Indiana University, USA.

E-mail: kelseyluella@gmail.com

(C) 2020 IJLCLE and Kelsey C. Deklerk 
we have the opportunity to readjust our thinking towards a more student-structured curriculum and instructional practices. This includes more opportunities for play, and participation in playful learning to enhance students' engagement and interest. This gives time that allows for students' creativity to thrive and build upon the playful skills they already possess.

The research here is focused on what teachers can do to enhance student learning through developmentally appropriate means, while continuing to push for depth of understanding in early childhood education classrooms. Though early childhood is generally defined as up to the age of 8 (NAEYC, n.d.), for the purposes of this paper, I limit my research to the formal education years within early childhood of prekindergarten through approximately 2 nd grade. How can multimodality be implemented at this age in ways that can increase literacy development and achievement for these young learners while attending to equitable and engaging educational practices? Multimodality will be explored as additional modes of literacy education that draw on students' current literacy expertise and interests. Literacy includes all modes that hold meaning, even beyond reading, writing and speaking. Recognizing the rich modes through which literacy can take place expands our lens of what qualifies as literacy skills and developmental practices.

My experience as an educator and a researcher is within $2^{\text {nd }}$-grade classrooms and younger. Early childhood education classrooms often require a different approach from classrooms working with older students, that is, approaches that focus on practices that are developmentally appropriate for young learners. Wohlwend (2008) urges educators to keep these age-appropriate practices in place, even amid a shift in educational requirements and expectations. She states that "standardized testing and uniform teaching leave little time for the messy wonder that regularly occurs during child-directed play and exploration" (p. 127).

Additionally, from a critical literacy lens, Vasquez (2017) teaches that literacy education should attend to the diversity of learners, supported through social justice and equity practices that allow for effective and equitable education. "Critical literacy [is] a perspective and way of being that should be constructed organically, using the inquiry questions of learners, beginning on the first day of school with the youngest learners" (p. 3). Play allows for this organic exploration and questioning to take place. It allows for students to explore relevant skills or challenges, based on their personal interests or experiences. Developmentally appropriate practices, therefore, not only attend to and allow for those "messy wonders" (Wohlwend, 2008) to occur in the classroom, but they also allow for an organic construction of inquiry based on the interests and knowledge of students, enabling critical literacy development.

Multimodality also recognizes that meaning-making is not limited to traditional linguistic outputs (Luke, 1992; Kress, 2009; Mills, 2016). Multimodality allows for an array of modes to represent literacy achievement and understanding. This versatility of linguistic understanding draws on critical literacy by allowing expression to be meaningful to students and their experiences. Therefore, in looking to explore developmentally appropriate practices that may allow for relevant and critical literacy instruction of young students, I turn to multimodality. My guiding questions here are:

1. How can multimodality be effectively implemented in an early childhood literacy classroom?

2. What modes of literacy are beneficial to literacy learning in early childhood education?

3. Can incorporation of multimodality also engage critical literacy practices within the early childhood classroom?

The research here focuses on ways that literacy achievement can be driven through multimodality specific to early childhood education. To do this, it is important to first understand 
multimodality in literacy in general. I will also explore critical literacy research and how this may be used in conjunction with multimodality in early childhood education. Once I have reviewed multimodality and critical literacy, I will focus on research that incorporates multimodality into early childhood education classrooms. Multimodality in early childhood education is split into several common modalities of incorporation, through play, toys, technology and devices, drama, and social interaction. I will look at each mode and research associated with them in early childhood. I will then discuss the findings on how multimodality is used with younger students, the influence this may have on students' learning, outcomes, and benefits, and any potential issues this may raise. I will finish by looking at possible gaps in the literature and the direction that future research may take to fill in these gaps.

\section{Research on Multimodality}

Literacy and language are holistic in nature (Luke, 1992; Kress, 2009; Mills, 2016). Literacy includes all modes that hold meaning, even far beyond reading, writing and speaking. They include the things we see, hear, and do, and they vary between cultures, social interactions, and structures. Modes may include insights into important aspects of cultures or groups of people (Kress, 2009). "Socially, a mode is what a community takes to be a mode and demonstrates that in its practices; it is a matter for a community and its representational needs" (pp. 58-59). Mode, then, is influenced by these cultural and social structures that help to create and interpret meaning. "Mode is broadly understood to be the effects of the work of culture in shaping material into representation" (Kress \& Jewitt, 2003, p. 1).

Multimodality then is understood to be "the use of several semiotic modes in the design of a semiotic product or event" (Kress et al., 2001, p. 20). Reading and writing are naturally multimodal processes because of their nature of both encoding and decoding words while also giving attention to the spatial layout of all elements, including text, images, and other literary representations on a page (Mills, 2016). Some tasks seen as one mode in process, like talking, in fact access multiple modes, like interpretation, processing of conversation, and inclusion of sensory or cultural processes present in the moment (Wohlwend, 2011). Therefore, many processes traditionally interpreted as a single mode are in fact multimodal.

Multimodality recognizes that meaning-making is not limited to only linguistic modes, but accounts for all aspects of meaning-making and understanding. Multimodality also recognizes that meaning does not exist outside of its context (New London Group, 1996). Meaning is made in increasingly multimodal, digital, and social ways. It is important to recognize the social and cultural uses in multimodality to create and understand meaning.

In an early childhood context, this means recognizing the social and cultural implications of literacy practices being acted out or upon. Therefore, multimodality analyzed throughout this paper allows for an even more diverse immersion into multiple modes of literacy. For instance, instead of

referring to the simultaneous decoding and encoding of words while reading, the multiple modes of literacy refers to combinations of literacy engagement that may be less recognizable or less accepted as literacy, such as play with others or with toys. Through a diverse recognition of acceptable literacy practices, educators can also appeal to the learning styles and understanding of diverse students. In this way, multimodality can be used in conjunction with critical literacies to appeal to students from diverse backgrounds, even as early as prekindergarten through 2nd grade. 


\section{Research on Critical Literacy}

Within the lens of critical literacy, Vasquez (2017) noted that the evolution of variability of linguistic repertoires, new technologies, and other factors makes it difficult to define what it means to be literate, not to mention how to teach literacy. Luke and Freebody (1999) state that "we agreed that there was no single definitive, truthful, scientific, universally effective, or culturally appropriate way of teaching or even defining literacy" (p. 2). In this sense, literacy and being literate are difficult to define, especially in terms of young students. The open-ended definition of literacy works well with the multimodalities mentioned above. Literacy does not have to mean pen and paper, but exploration of the world through more senses, and engaging in one's knowledge and background. This open-ended participation in literacy allows for acknowledging differences in cultural understanding while attending to literacy development.

Norton (1999) notes that language and identity are "complex, contradictory, and multifaceted and reject any simplistic notions of identity" (p. 419). She links identity theory with classroom practices. In analyzing work in language and identity, she notes that both "point out that identity constructs and is constructed by language" (p. 419), and that linguistic identity should be supported in the classroom, where a student's identity should thrive, not be diminished. By incorporating a multimodal classroom, full of developmentally appropriate modes of literacy exploration-play, toys, social interactions-students' literacy practices also construct their identity and their identity constructs the literacy practices.

These articles delve into literacy and language practices in the classroom, the ways that we include, construct, deconstruct, restore, and critically engage in language. This engagement is especially important here because of the connection that language (including literacy) has to a student's identity. A student's background, identity, and culture need to be taken into account and be used in the classroom (Ladson-Billings, 1995). In this way we are allowing a student their own identity instead of pushing our cultural identity and ways of knowing onto the student (Freire, 2000).

What we often see with literacy and literacy education is a binary ideal of what it means to use literacy, teach literacy, and be literate. The articles above articulate ways in which literacy is used in different communities, cultures, and even families. The exclusion of different ways of knowing only adds to an ideal of what it means to be literate and who possesses that skill, while diminishing the understanding and knowledge of a wide range of literate individuals. Friere (2000) is particularly concerned with the ways in which traditional pedagogy not only ignores the knowledge of particular cultures, but continues to oppress those individuals based on their background and understanding. By silencing the literacy skills which others possess, we in turn oppress those individuals and force them to conform to a societal paradigm perpetuated by power relations.

When speaking about a student who scored poorly on standardized testing, Delpit (1992), who came from a difficult background, but was still powerfully successful and influential in her field, said, "people, given the proper support can 'make it' in culturally alien environments. [Success stories like this] makes clear that standardized test scores have little to say about someone's actual ability. And it demonstrates that supporting students' transformation demands an extraordinary amount of time and commitment, but that teachers can make a difference if they are willing to make that commitment" (pp. 296-297). This is achievable by teaching outside the bounds of "normal" literacy education, and providing students with opportunities to delve into critical literacies, which can be infused with multimodalities. Traditional educational practices did not reveal this student's actual abilities (Delpit, 1992). By attending to critical involvement in culture and multimodal literacy practices, teachers can better attend to the needs of their students. 
Critical literacy recognizes the many ways in which an individual, family, or community is literate or uses literacy. The pedagogy then recognizes and adapts to these broad literacies. This adaptation may be done through the inclusion of alternative or additional modalities in the classroom. There is no correct or universal model of critical literacy. Instead, "how educators deploy the tools, attitudes, and philosophies is utterly contingent ... upon students' and teachers' everyday relations of power, their lived problems and struggles and the ways in which teachers are able to navigate the (P)politics of the places and spaces in which their work unfolds" (Vasquez, 2017, p. 9).

Through critical literacy, there is the potential to speak not only the dominant language and culture in the classroom, but also to speak out for marginalized students. Multimodality allows for multiple avenues of learning and engagement in literacy. It allows students to find a path that works for them, their culture, language, background, and understanding. Within the context of early childhood education, multimodality offers developmentally appropriate modes of engagement in literacy education. These modes have the potential to expound on critical literacy practices and ways of learning and teaching. Multimodality can then work in conjunction with critical literacy in an early childhood education classroom. Literacy modes can connect these young students not only with developmentally appropriate practices, but critically engage students in learning as well. It can draw upon their culture and uses of literacy to expand on literacy learning.

\section{Research on Multimodality in Early Childhood Education}

Research on multimodality is thin in the area of early childhood education. However, many examples of its use and impact in the classroom can be found in the literature. In the early childhood education classrooms of prekindergarten through approximately 2 nd grade, research has been conducted on literacy education through means other than traditional reading and writing, or direct instruction. Researchers have explored literacy development through avenues like play, drama or acting, incorporation of digital literacies, and even through social interaction among other children and adults (see, for example Flint, 2018; Lysaker, Wheat \& Benson, 2010; Roskos et al., 2003; Wohlwend, 2008, 2011; Yoon, 2014).

Wohlwend (2011) looked at modes of literacy within early childhood education and outlined the literacy practices that are developed through the use of particular modes. She notes how speech, music, and sound effects lead to talking and singing in later development. "Visual modes, including print, image, gaze and mediated action with books, writing tools, or art materials" (p. 82) lend themselves to the development of reading, writing, and design. Play leads to understanding and use of actions like gestures, body language, and movement, as well as action involving toys, dolls, props, and so on.

Multimodality, then, makes sense when applied to early childhood education, as the students don't typically have reading and writing skills at a level where they can engage in them in traditional academic settings. Therefore, multiple avenues for literacy should be available to them, avenues which foreground the development of these sought-after literacy skills. This is where multimodality becomes an important tool in early childhood. Wohlwend (2008) argues this further by saying that "children's flexible orientation to designing and interpreting meaning affords multiple paths into literacy" (p. 126). Play, for instance, as outlined below, can be used as a stepping stone to reading and writing (Roskos et al., 2003; Wohlwend, 2008; Yoon, 2014). It may be a means of expression, communication, and storytelling, therefore making play a possible mode of literacy and an avenue through which multimodal literacy may be achieved. 
Here I highlight some of the directions of literacy education shown in research. These avenues explore and incorporate multiple modes of literacy learning within early childhood education, allowing children to develop literacy through multimodality. This review of the literature is separated into modes that are seen in literature in regards to literacy education in early childhood.

\section{Play}

The most prevalent and arguably the most developmentally appropriate avenue of literacy education found in early childhood education research is play. Play incorporates many modes of literacy, including any combination of visual modes such as pictures, toys, body gestures, and body language, and auditory modes such as speech, singing, and listening. Play with other students also creates a need for the modes of interpretation and response (Wohlwend, 2011). In some cases, play may also include modes relevant to reading and writing (Roskos et al., 2003; Wohlwend, 2008; Yoon, 2014). Play lends itself to many modes of understanding and meaning-making.

Flint (2018) argued that the field of early childhood education should be reconceptualized to include play as a valid form of reader response, as play is an important source for children's academic learning. During her study in a $1^{\text {st }}$-grade classroom, she focused on play as a form of reader response, or "responsive play" (Flint, 2018). Her findings suggest that children can learn responses to literature through play and that the children's experiences and funds of knowledge (González et al., 2005) should add to the learning environment instead of being discouraged. In this research, play directly led to skills necessary for reading and writing development through inclusion of additional modes with play. Lysaker et al. (2010) researched the use and quality of play in an early childhood education classroom during times when children were working on reading and writing. The study found play was used in three ways, "through the use of singing and chanting, the expression of intense emotion, and the use of pretend and fantasy" (p. 209). Through play, children create a "third space" (Gutiérrez, 2008) where they combined academic learning and their social, playful lives that played more into their zone of proximal development (Vygotsky, 1978) for academic growth. Engagement in this third space allows children to insert importance in school interactions by also combining home values and ways of knowing into academic interactions (González et al., 2005). Literacy practices could be viewed with relevance to students' lived experiences. Through the infusion of academic learning and social lives, students engaged critically in multimodal literacies.

Popular media may also be used as a background literacy for the children to call upon in literacy learning through play. Play allows background knowledge to develop storylines and language. Popular media may provide a foundation on which these skills may be further expanded and used (Wohlwend, 2017). Giving students opportunities to play rather than just reading and writing allows more children to participate in literacies through stories and modes that are familiar and comfortable. They hold expertise in familiar stories and therefore enact deeper literacy skills (Medina and Wohlwend, 2014; Hobbs \& Jensen, 2009). Play within the classroom allows children to draw upon their background knowledge to engage in meaningful storylines. With the use of popular media, the storylines were furthered, creating opportunities for deep engagement in literacy modes such as recall, storying, and modes associated with play, as mentioned previously.

\section{Toys}

Along the same lines as play, toys are tools for play, and in turn, through which literacy can be achieved. Larson et al. (in press) outline ways that toys can be incorporated into the classroom as a means of literacy development for young learners. In one example, the authors share the ways that toys can be used as a tool for literature comprehension and story retelling by using toys that connect 
to the story, and having children bring the story to life through their play with toys. By using toys for retell, teachers are engaging modes of literacy through play that might not otherwise be present in the classroom.

The authors here also argue for allowing children to bring toys from home to be used in the classroom. This use goes beyond the traditional "show and tell." Instead, they assert that the use of toys from home will allow educators to glimpse items, stories, and literacies that are important and familiar to the children at home. These toys allow for a connection with home literacy practices and give educators an opportunity to build upon the knowledge and interests of the child (Larson et al., in press).

Similarly, Buchholz and Coggin (2013) describe young students making their own toys with paper, crayons, and scissors available in the classroom to be used as part of the students' academic literacy time. The students proceeded to recreate or reimagine familiar stories, expanding on familiar literacies, and remaking literacies through their play with these paper toys. The creation of toys was itself a process of development and literacy production. Children used visual and gestural modes of literacy, like drawing and design. With the finished product, children are able to engage in story creation, adaptations, or retelling, either solely or collaboratively with other students. The use of toys in this case was multimodal in terms of production, as well as the literacy practices that were produced with the use of the finished toy.

In the examples above, toys were used in conjunction with play in the classroom. Students brought toys from home to use in school, used toys provided for them in the classroom, or made toys. In each case, toys served as a tool by which modes of literacy were enacted as they surfaced through play.

\section{Digital Literacy}

Digital literacy in the form of devices and applications is incorporated as a mode to develop literacy skills in the early childhood education classroom. Oftentimes, digital literacies are also used together with play, utilizing a combination of modes of literacy that both play and digital literacy are able to draw upon. Wohlwend (2015) observed as children in a preschool-aged classroom interacted with technology, play, and literacy, using skill sets specific to technological, literary use. Toddlers understood that there are new modes and ways to interact with digital literacies (swipe, pinch, etc.). Through classroom observations, Wohlwend saw digital literacies emerge as young students played together to create meaning through applications on tablets. Children collaborated to create complex stories using digital puppets, and often required additional children so they could manipulate more than one character at a time. Children engaged in modes of literacy necessary for digital interactions as well as play and collaboration with other students.

Digital apps offer children a place to produce their own stories, work, and digital animations in ways that encourage collaboration, support their literacy development in the classroom and their digital literacies, and engage students through play interests. The research here shows that children collaborating to use these apps support one another in this development in practices that are engaging and fun to them (Wohlwend, 2015).

In addition to device-based apps, Wohlwend (2013) observed the incorporation of both digital recording devices and toys in the classroom. Students were given the opportunity to play and create stories, using provided toys as characters in their telling. Students were then afforded the opportunity to record and act out their stories on cameras and other devices as they created their own stories. In this "Literacy Playshop" (Wohlwend, 2013), teachers used technology in the classroom with video 
production of storytelling. They started by allowing children to create toys, then to play with toys, and later with production equipment, then begin using all materials to create stories and videos as a form of literacy production. This literacy structure was captured with the use of recording devices after children practiced the skill of incorporating these devices into their literacy time.

The process of literacy playshop is a multimodal literacy incorporating technology into early childhood education classrooms with recording devices and toys. This can be used to incorporate technology in engaging ways for literacy production. Play is used to guide children's needs and development of literacy skills like writing, story production, cooperation, and story pieces like characters, setting, plot, etc. These modes of literacy, plus those associated with play, toys, and even technology were ever-present in this multimodal curriculum. Critical literacy was present in the ways that students drew on familiar stories, created new stories of importance to them, or reimagined stories to fit with personal interests or experiences. Through literacy playshop, children participated in multimodal storytelling that had the possibility of critically imaging or reimaging stories.

\section{Drama}

In the example of Literacy Playshop above (Wohlwend, 2013), students created, re-envisioned, altered, and eventually acted out their stories, both on camera, and in some cases, live for classmates or teachers. In addition to acting for the camera, they then edited, viewed, and used the recorded stories to further engage with their stories through the recorded dramatizations. In this way, drama was intertwined as a mode with play and technology to engage students in literacy.

Therefore, drama is again a mode found in conjunction with play within literature. Through other examples such as thematic play centers, students act out real-life scenarios such as farms, shopping, or childcare. Children act and play upon life moments that are familiar or enact their background knowledge of the world and lived experiences (Larson et al., in press). In this way, play, together with drama, draws on students' funds of knowledge (Gonzáles et al., 2005) to act out scenarios that are familiar from their lives. Because of this, students simultaneously create stories, draw from background knowledge, act out these scenarios, and collaborate in the storytelling with other students.

In their ethnographic study, Medina and Campano (2006) found that drama is a prime example of an alternative literacy practice that seems to be marginalized in modern classrooms to make way for test driven practices. This is especially true in low-income schools where resources are more strained. However, drama can serve as a meaningful way to perform literacies that engage students' lives. Though their research was in elementary grades older than 2nd grade, the implications can be easily applied to younger students. Students used drama to critically reenact social or cultural situations that were meaningful to them. They then used drama as they reimagined the actions or structures of the stories to be more meaningful or make compromises with outcomes. This taught students to interact with or negotiate diverse perspectives while generating knowledge. Through dramatizations of reallife situations, students were able to engage in auditory, visual, and gestural modes of literacy. They also drew upon background knowledge and modes of cooperation and collaboration with other students as they acted out these scenarios. Students also engaged in critical literacy practices by connecting to their personal lives, questioning, reworking, or restructuring their interactions through drama. In this way, drama becomes a complex, multimodal literacy to critically engage the lives of students in early childhood education. Teachers can guide these young students to direct their play or literacy engagement through dramatization. This allows the students to express their experiences, reimagine their worlds, and think critically about their lives and futures while engaging collaboratively in multimodal literacies. 


\section{Social Interactions}

Additional research found that social interactions, either in the classroom or on the playground, served as a multimodal means of literacy development in education. In a case study performed by Yoon (2014, the author highlights a group of kindergarten students that engage in play during their writing tasks in the classroom. The writing tasks were made meaningful by their social interactions that took place outside of the classroom. This generally took place during unstructured play time, usually recess, and added to structured literacy time. These interactions drove the ways they thought about and acted out writing tasks and were an important aspect of their literacy uses. When informal play time was allowed into the classroom during formal literacy time, students engaged in their writing tasks in meaningful ways. This incentivized children to also deepen their literacy tasks during unstructured play time. In this study, children took writing basics from classroom lessons and applied their writing knowledge to "extend and expand their play enactments" (p. 114) to further their play in meaningful, academic ways. The classroom lessons were incorporated into social interactions through play and vice versa. Students began to use the social, playful reciprocity in their writing in the classroom setting.

They also took academic learning into their social interactions. Writing was used as an extension of play and social negotiations. Academic, cultural, and social lives were interconnected in ways that transformed learning and made literacy meaningful to the social and cultural lives of the students. In this case, modes of reading, writing, playing, and social interaction all connected to make the writing in the classroom significant for the individual students.

Wohlwend (2017) also observed the social interaction of a classroom of 5-year-old students engaged in literacy playshop practices. In the classroom, students used popular media toys to play, recreate, and reimagine familiar stories. Students wrote scripts, acted out stories, and even filmed their recreated or reimagined stories based on familiar media. She found that children drew upon popular media and storylines that they knew well to improvise dialogue and storylines into their play. This developed themes of literature and friendships found in the classroom. This process revealed that literacy can take place through alternative modes, expanding what qualified as developmental literacy practice. This play created opportunities for social interactions that continued to build upon the literacy development taking place. It also gave more children access to play groups, allowing for more social connectivity, because of the connection the students made through popular media. Bringing a media-influenced curriculum into the classroom transformed students from onlookers into participants and made a difference in participation and desire within literacy education. It allowed for a means of connection between students, ones who might not otherwise play together, as they connected through play infused with familiar stories. These familiar stories inspired social interactions that were infused with play, once again demonstrating the ways that modes of literacy were engaged through social and playful means.

\section{Findings}

\section{Student as Expert}

Multimodality in early childhood education often utilizes developmentally appropriate modes of literacy (Wohlwend, 2013) like play, acting, and so on. Through modes such as these, students are positioned as the experts in their own learning (Larson et al., in press). It allows children to develop literacy skills through avenues that stem from their funds of knowledge, backgrounds, and current understanding of literacy to allow for scaffolding of learning to develop deeper skill sets (Ertmer \& Glazewski, 2019). 
Multimodality does not tend toward just one cultural interpretation or aspect of literacy development. It also does not view one stage of life as the most important or meaningful. It allows for different ways of approaching literacy, as well as meaning-making. It sets up children of all cultures and backgrounds as capable learners, engaged in the literacy process through modes that are exciting to them (Wohlwend, 2011). Aspects of multimodality in early childhood education, as outlined above, allow children to explore their worlds and lived experiences. They position children as designers of their learning experiences.

\section{Collaboration}

Research has found that collaboration was often a byproduct of some forms of multimodal literacy education in the pre- $\mathrm{K}$ through $2^{\text {nd }}$-grade classroom (Larson et al., in press; Wohlwend, 2013, 2015; Yoon, 2014; see also Medina \& Campano, 2006). Within the context of all literacy modes-play, use of toys, drama, technology, and social interaction-research showed students engaged with one another in their learning processes.

"Collaborative learning has been shown to not only develop higher-level thinking skills in students, but boost their confidence and self-esteem as well" (Gates, 2018, para. 8). Collaboration is an opportunity for teachers and students to maximize educational growth while also working to improve social and interpersonal skills with support in an academic setting. In these cases, students are afforded the opportunity to develop and study with various types of learners while also deepening leadership and collaboration skills that will continue to prove important throughout their lives (Gates, 2018).

\section{Literacy Achievement}

Multimodality in the context of play, drama, technology, and the other modes outlined in this paper, clearly enabled students to develop literacy skills through pedagogical routes other than direct instruction. Though achievement was not measured against those of direct instruction or single modal practices, in each case of multimodality used in early childhood education, students were actively engaged in learning. The curriculum was relevant, meaningful, and at levels that were developmentally appropriate for this age of students. Students were also able to participate in critical literacy as they explored multimodal literacy practices that were relevant and meaningful to their personal lives and experiences.

Multimodality is shown to be a tool by which literacy achievement can be reached. Through multiple modes like the ones outlined above, students were engaged in the curriculum because of the modes' connection to their lives and backgrounds, the connection to other students and teachers, the engaging nature of the modes used, and the attention to the students' interests. In these ways, multimodality allows for academic achievement because of its attention to and allowance for student growth within their zone of proximal development.

\section{Potential Issues}

Although the research reviewed here did not specifically mention many issues with multimodality in early childhood classrooms, one potential issue I find is within social interactions themselves. Social interaction will exist regardless of the instructional practices taking place in the classroom. However, multimodality may bring those social practices into the academic work of the students. Yoon (2014) described students using writing or drawing as a social tool to share information about their relationships with other students. This social writing and collaboration was present in the classroom because of the way multimodality tied the social lives of the students into their academic 
work. How this can become an issue, however, is that the social writing at times could exclude other students by bringing recess disputes into academic work, passing notes, drawing pictures of friend groups, creating handouts for other students and leaving someone out. The writing was at times exclusionary towards other children, used as a "weapon" to promote conflict (p. 115). Though the inclusion of social lives within the classroom may not be a bad thing, it may also require additional mediation on the part of the teacher. It may bring up issues between or among students that perhaps would not otherwise exist within the academic walls of the classroom. However, it may also offer an insight into the children's social worlds, to allow teachers a space to offer mediation that they might not otherwise encounter. This can help teachers to know what interactions are critical and important to students, and that may need additional structured support as children work through them.

\section{Digital Literacies}

When it comes to the incorporation of devices in particular, there are several concerns voiced by other researchers. Neiterman and Zaza (2019) interviewed teachers and found they had the issue of time that students spend off task with devices. Results showed that teachers found the use of devices to be more of a distraction than a support. They felt there was a need for constant regulation to try to keep students on task. However, they felt when done correctly, that devices could be used for innovative instructional purposes within the classroom.

Other research shows that screen time is linked to lower brain development in children (Hutton et al., 2019), and therefore should not be used in school in general. Students should be learning through avenues that do not require screen time. Though this is certainly a concern, devices, when used appropriately, with applications that are effective and beneficial, can also result in successful skill development (Rowsell \& Wohlwend, 2016). Device use, purpose, and time should be factors when considering possible technology implementations with young students.

Because of the need for relevant and well-thought-out applications in the classroom, Rowsell and Wohlwend (2016) present a framework for which digital applications can be analyzed for their effectiveness in literacy education uses. Their rubric, which includes multimodality, also analyzes applications on five additional dimensions: multiplayer, productive, open-ended, pleasurable, and connection. Criticisms of devices in the classroom include the use of ineffective applications. This rubric enables a more knowledgeable understanding of applications, to either introduce or continue their use into the classroom. "More dimensions lead to more complex learning so that robust and engaging apps ... allow learners to produce their own multimodal content and follow their passions through open-ended journeying in collaboration with multiple players and shared across networks" (p. 204). Research on specific apps could give additional information on the ways in which devices and applications can be incorporated as play into literacy education.

A final drawback is that devices are not readily available for all students. The cost for schools can be too high, especially in lower-income areas. Outside of school, devices again may be restricted based on socioeconomic status or cultural uses. Funding may also be an issue for upkeep of the devices themselves. For instance, outdated software or technology may result in crashes, slow response times, and frustration for students and teachers (Wohlwend, 2015). Funding is an issue that may only affect lower-income areas or students. Because of this, however, there is a need for inclusion to eliminate any possible gaps in achievement this may cause because of socioeconomic status alone. 


\section{Further Research Directions}

Many of the researchers investigating the implication of play in the classroom are also invested in incorporating play into academic practices. All authors I reviewed here have a positive mindset regarding the use of play in the classroom. Most are even outwardly biased towards the incorporation of play. Though play may be eminently beneficial, there is no research looking at the negative aspects of incorporating play in the classroom. It is possible that researchers would come away with only positive, or mostly positive aspects, but research with the mindset of finding negative aspects could greatly impact the argument for or against play in education. Either this research could be inconclusive and support current arguments in the field, or there could be findings that would influence further research and a more rounded argument for or against play-inclusive classrooms.

There is also a need for more research specific to multimodality in early childhood classrooms. Though multimodality is inevitably included in research that inherently includes additional modes of learning like those mentioned above, there are not many researchers in the field of multimodality that are specifically studying early childhood education classrooms. This research has the potential to also include aspects of critical literacy, adding elements of culture and identity to its purposes. Multimodality in combination with critical literacy has the potential to add another layer of important research within the field of early childhood education.

Finally, because of the research and criticisms around devices in the classroom, additional research should be done to identify applications or uses for technology that will be beneficial for student development. Research on classroom implementation, how often, what is used, how it is used, and by whom would also be beneficial. Further analysis, like that done by Rowsell and Wohlwend (2016) to develop rubrics and analyze applications, could support decisions to include particular apps within the context of classroom literacy development in early childhood education. Teachers and researchers alike could also benefit from using the rubric outlined in their article to determine if an application should be used within a classroom.

\section{Conclusion}

This article explores how multimodality can be effectively implemented in an early childhood literacy classroom. Research shows an array of modalities implemented for young learners, mainly aimed at engaging the students in practices that are exciting and developmentally appropriate for their age. These modes can also approach literacy from directions that make sense to young learners who may not yet be able to read and write.

The research showed literacy education taking place through modalities that included, but were not limited to, play, toys, devices and applications, social aspects of learning, and drama. Through these multimodalities, students were engaged in other modes of literacy learning, including multiple aspects of visual, auditory, gestural, and other modalities necessary for communication and forms of interaction. These modalities within early childhood education can result in successes such as drawing on students' funds of knowledge to set the children up as the expert in their own learning, building on their strengths, achieving desirable literacy outcomes, and allowing for collaborative learning.

Research on critical literacy also shows the possibility of multimodality to incorporate aspects of critical literacy into education for young learners. These aspects provide the potential for engaging critically through multimodality, even as young as preschool. Critical literacy outlines an important pedagogy to help students develop and shape both identity and learning, and include aspects of culture and background knowledge in literacy development, steps that can be taken in conjunction with multimodality. 
Possible issues that were discussed include the possibility of negative social interactions, devices including technical issues, quality, or overuse issues that arise due to technological incorporation. Possible rubrics for finding quality applications were discussed and outlined based on literature set to review classroom technology use.

Finally, further research needs were discussed. There is a great deal of research in the fields of multimodality and early childhood education that are independent of one another. Connections can be made by looking at the modalities used within early childhood literature, or analyzing multimodal literature for its possible uses within early childhood education classrooms. However, additional work that is both multimodal in nature and set within the prekindergarten through 2nd grade classrooms would be helpful to further the research in these two fields. Inclusion of critical literacy within multimodal research in these ages would add an element of culturally relevant research. The possibilities discussed in this review outline ways that this research could be impactful within all three fields of study.

Multimodality, critical literacy, and the implementation of strategies to support literacy development are so important in an age of high-stakes testing. Multimodalities offer developmentally appropriate modes of literacy engagement in early childhood education classrooms.

\section{Disclosure Statement}

No potential conflict of interest was reported by the author.

\section{References}

Bassok, D., Latham, S., \& Rorem, A. (2016). Is kindergarten the new first grade? AERA Open, 1 (4), 1 31. doi:10.1177/2332858415616358.

Blatchford, P., Pellegrini, A. D., \& Baines, E. (2016). The child at school: interactions with peers and teachers. Routledge.

Buchholz, B. A., \& Coggin, L. S. (2013). Media processes in a K/1 playshop. In K. Wohlwend (Ed.), Literacy playshop: New literacies, popular media, and play in the early childhood classroom. (pp. 7-25). New York: Teachers College Press.

Christakis, E. (2016, January/February). The new preschool is crushing kids. The Atlantic, 317, 17-20.

Delpit, L. D. (1992). Acquisition of literate discourse: Bowing before the master? Theory Into Practice, 31(4), 296-302. doi:10.1080/00405849209543556.

Ertmer, P. A., \& Glazewski, K. D. (2019). Scaffolding in PBL environments. In The Wiley handbook of problem-based learning (pp. 321-342). Wiley. doi: 10.1002/9781119173243.ch14.

Flint, T. K. (2018). Responsive play: Creating transformative classroom spaces through play as reader response. Journal of Early Childhood Literacy, 20(2), 385-410.

Freire, P. (2000). Pedagogy of the oppressed (30th anniversary edition). Continuum.

Gates, S. (2018, October 18). Benefits of collaboration. Retrieved from http://neatoday.org/neweducators/benefits-of-collaboration/.

González, N., Moll, L., \& Amanti, C. (2005). Funds of knowledge: Theorizing practices in households, communities and classrooms. Lawrence Erlbaum Associates.

Gutiérrez, K. D. (2008). Developing a sociocritical literacy in the third space. Reading Research Quarterly, 43(2), 148-164. doi:10.1598/rrq.43.2.3.

Hobbs, R., \& Jensen, A. (2009) The past, present and future of media literacy education. Journal of Media Literacy Education, 1, 1-11. 
Hutton, J. S., Dudley, J., Horowitz-Kraus, T., Dewitt, T., \& Holland, S. K. (2019). Associations between screen-based media use and brain white matter integrity in preschool-aged children. JAMA Pediatrics, 174(1). doi: 10.1001/jamapediatrics.2019.3869

Kress, G. (2009). What is mode? In C. Jewitt (Ed.), The Routledge handbook of multimodal analysis (pp. 5467). Routledge.

Kress G., \& Jewitt, C. (2003). Introduction. In C. Jewitt \& G. Kress (Eds.), Multimodal literacy (pp. 118). Peter Lang.

Kress G., Jewitt, C., Ogborn, J., \& Tsatsarelis, C. (2001). Multimodal teaching and learning: The rhetorics of the science classroom. Bloomsbury.

Ladson-Billings, G. (1995). But that's just good teaching! The case for culturally relevant pedagogy. Theory into Practice, 34(3), 159-165. doi:10.3726/978-1-4539-1584-4/43.

Larson, K. T., Wohlwend, K. E., Deklerk, K. C., \& McClure, A. (In Press). Beyond show and tell: Animating literacies and using toys as mediators. Understanding the worlds ofyoung children: Learning literacy through social-cultural practices. Charlotte, NC: Information Age Publishing.

Luke, A. (1992). The body literate: Discourse and inscription in early literacy training. Linguistics and Education, 4, 107-129.

Luke, A., \& Freebody, P. (1999). Further notes on the four resources model. Reading Online http://www.readingonline.org/research/lukefreebody.html

Lysaker, J. T., Wheat, J., \& Benson, E. (2010). Children's spontaneous play in writer's workshop. Journal of early childhood literacy, 10(2), 209-229. doi: 10.1177/1468798410363835.

Medina, C., \& Wohlwend, K. E. (2014) Literacy, play, and globalization: Critical and cultural performances in children's converging imaginaries. Routledge.

Mills, K. (2016). Literacy theories for the digital age: Social, critical, multimodal, spatial, material and sensory lenses. Multilingual Matters.

NAEYC. (n.d.). National Association for the Education of Young Children: About us. Retrieved from https://www.naeyc.org/about-us.

Neiterman, E., \& Zaza, C. (2019). A mixed blessing? Students' and instructors' perspectives about offtask technology use in the academic classroom. The Canadian Journal for the Scholarship of Teaching and Learning, 10(1). doi: 10.5206/cjsotl-rcacea.2019.1.8002.

New London Group. (1996). A pedagogy of multiliteracies: Designing social futures [Electronic Version]. Harvard Educational Review, 66, 60-93.

Norton, B. (1997). Language, identity, and the ownership of English. TESOL Quarterly, 31(3), 409. doi: $10.2307 / 3587831$.

Roskos, K. A., Christie, J. F., \& Richgels, D. J. (2003). The essentials of early literacy instruction. Young Children, 58(2), 52-60.

Rowsell, J., \& Wohlwend, K. E. (2016). Free play or tight spaces? Mapping participatory literacies in apps. The Reading Teacher, 70(2), 197-205. doi:10.1002/trtr.1490.

Vasquez, V. M. (2017). Critical literacy. Oxford research encyclopedia of education. doi: 10.1093/acrefore/9780190264093.013.20.

Vygotsky, L. S. (1978). Mind in society: The development of higher psychological processes. Harvard University Press.

Wohlwend, K. E. (2008). Play as a literacy of possibilities: Expanding meanings in practices, materials, and spaces. Language Arts, 86(2), 127-136.

Wohlwend, K. E. (2011). Playing their way into literacies: Reading, Writing, and belonging in the early childhood classroom. Language \& Literacy Series. Teachers College Press.

Wohlwend, K. E. (2013). Literacy playshop: New literacies, popular media, and play in the early childhood classroom. Teachers College Press. 
Wohlwend, K. E. (2015). One screen, many fingers: Young children's collaborative literacy play with digital puppetry apps and touchscreen technologies. Theory into Practice, 54(2), 154-162.

Wohlwend, K. E. (2017). Who gets to play? Access, popular media and participatory literacies. Early Years: An International Research Journal, 37(1), 62-76. doi: 10.1080/09575146.2016.1219699.

Yoon, H. S. (2014). Can I play with you? The intersection of play and writing in a kindergarten classroom. Contemporary Issues in Early Childhood, 15(2), 109121.doi:10.2304/ciec.2014.15.2.109. 